Research Article

\title{
How Is Gross Profit Margin Overestimated in China?
}

\author{
Fulei Shi $\mathbb{D},{ }^{1}$ Bingbing Huang $\mathbb{D},{ }^{2}$ Chuanqi $W u,{ }^{3}$ and Liang Jin ${ }^{4}$ \\ ${ }^{1}$ School of Management and Engineering, Capital University of Economics and Business, Beijing 100070, China \\ ${ }^{2}$ Renmin Business School, Renmin University of China, Beijing 100872, China \\ ${ }^{3}$ School of Social Sciences, Tsinghua University, Beijing 100084, China \\ ${ }^{4}$ Yonyou Network Technology Co., Ltd., Beijing, China \\ Correspondence should be addressed to Bingbing Huang; 514319917@qq.com
}

Received 30 August 2021; Revised 20 November 2021; Accepted 23 November 2021; Published 14 December 2021

Academic Editor: Barbara Martinucci

Copyright (C) 2021 Fulei Shi et al. This is an open access article distributed under the Creative Commons Attribution License, which permits unrestricted use, distribution, and reproduction in any medium, provided the original work is properly cited.

\begin{abstract}
At present, the index of gross profit margin is overestimated in China. However, this problem has not attracted enough attention. This paper explores the theoretical limitations of the current revenue that lead to the overestimation of the gross profit margin. Then, we present the concept of revenue to correct the limitations of the current revenue. Moreover, we test the impact on the information content of gross profit margin under revenue caliber. The findings are as follows: (1) The current revenue includes some unrealized items such as in-price tax, so it is not completely consistent with the definition of revenue from the perspective of accounting, which will lead to the overestimation of gross profit margin. Therefore, the current revenue should exclude the inprice tax, bad debt loss, and cash discount in order to obtain the revenue. The gross profit margin based on the revenue can reflect the profitability of the company's basic business more objectively. (2) The empirical test shows that the gross profit margin based on the revenue has higher information content compared with the gross profit margin based on the current revenue. (3) The current gross profit margin is overestimated by 1.36 percentage points because of the limitations of the current revenue.
\end{abstract}

\section{Introduction}

Gross profit margin is the most commonly used index to evaluate the profitability of enterprise's basic business performance. Gross profit is the difference between revenue and cost of sales $[1,2]$. Gross profit margin is the proportion of gross profit to revenue. Gross profit margin is the starting point index to analyze the profitability of enterprise. It is of great significance to use it to investigate the market competitiveness of enterprise's products horizontally and the stability and development trend of enterprise's operation vertically. If the gross profit margin calculated based on the current revenue cannot reflect the real basic business profitability of enterprise, it will mislead the decisionmaking of stakeholders and reduce the usefulness of accounting information. The existing literature on gross profit margin mainly focuses on enterprise performance evaluation and prediction and pays less attention to the problems of gross profit margin itself $[3,4]$. The research goal of this paper is to analyze the limitations of the current gross profit margin and explore how high the gross profit margin of the company listed in China is.

On March 29, 2019, Kweichow Moutai (A-shares code: 600519) released its 2018 annual report, which shows that the annual revenue reached 73.639 billion yuan in 2018 and the gross profit margin was $91.14 \%$. However, the most important reason that leads to the high gross profit margin is the in-price tax. The in-price tax includes the excise tax, urban construction tax, and education surcharge, and the total in-price tax for Kweichow Moutai is up to 10.648 billion yuan in 2018, accounting for $14.46 \%$ of the revenue and $94.32 \%$ of the total in-price tax. If the in-price tax is excluded, the gross profit of Kweichow Moutai will drop by 10.648 billion yuan, and the gross profit margin will decrease by 1.5 percentage points. As a tax included in the revenue, it essentially belongs to the "money collected by an enterprise on behalf of a third party." Although it is collected together with the revenue, it does not lead to an increase in the owner's equity, which does not meet the definition of revenue. Similarly, in the 2018 annual report, another A-share 
firm, Tianhe Defense (A-shares code: 300397), shows that the revenue was 175 million yuan, and the gross profit margin was $33.71 \%$. However, the bad debt loss of Tianhe Defense in 2018 was 107 million yuan; that is to say, 107 million yuan of revenue was not received. If 107 million yuan of uncollected bad debt loss is excluded from the revenue, the gross profit margin will be $-11.46 \%$. The bad debt loss is due to the uncollectible accounts receivable sold on credit, and the recognized revenue corresponding to the bad debt loss has not been realized. Therefore, the bad debts that cannot be recovered should not be included in the revenue. From the above two typical examples, it is shown that if the in-price tax, bad debt loss, and other items account for a high proportion of the revenue, it will have a great impact on the gross profit margin.

This paper contributes to the existing literature in several ways. On the one hand, although the gross profit margin is one of the most widely used financial indicators in practice, there are few literature studies on the limitations of the gross profit margin. This paper is committed to analyzing the limitations of the gross profit margin and providing the improvement method in theory, which fills the blank of the theoretical research of the gross profit margin. On the other hand, this paper empirically tests the negative impact of overestimation of current revenue on information content of gross profit margin, which provides support for the theoretical analysis and supplements the empirical research on the gross profit margin. Our findings also have implications for various stakeholders in corporate financial reporting. This paper can help us to recognize the limitations of gross profit margin. Then, it can help us to get rid of the misunderstanding of relying too much on gross profit margin.

The remainder of the paper is organized as follows: Section 2 reviews the literature and develops our hypothesis. Section 3 describes our data and methods. Section 4 presents our tests, results, and discussion. Section 5 concludes the paper.

\section{Literature Review and Hypothesis Development}

2.1. The Three Limitations of Current Revenue. There is a debate on the definition of the concept of revenue in academia, and there is also a difference in the application of the concept in practice. Scholars who advocate a wide range of revenue in academic circles believe that revenue includes not only economic benefits from operating activities, but also economic benefits from nonoperating activities such as nonoperating benefits or investment benefits $[5,6]$. The international accounting standards that support the wide range of revenue are mainly reflected in the fact that income is regarded as an independent accounting element, which includes revenue and profits. The scope of revenue includes not only the main revenue, but also other revenue and investment gains (such as interest and dividend). Scholars who advocate narrow revenue in academic circles believe that revenue is only the economic benefit obtained by operating activities, which means that the economic benefits obtained by nonoperating activities should not be included in the category of revenue [7-10]. China's Accounting Standards (CAS) and US Generally Accepted Accounting Principles (GAAP) support narrow revenue caliber, which is mainly manifested in the fact that revenue is regarded as an independent accounting element, which generally refers to the economic benefits obtained from daily operation, excluding nonoperating benefits. What is more, other revenue which is not belonging to the core operating activities is excluded from the revenue category by the US GAAP. Although the definition and application of the concept of revenue can be divided into broad and narrow dimensions in academic and practical circles, both of them claim that the revenue is the inflow of economic benefits that the enterprise really obtains, which will lead to the increase of owner's equity and have nothing to do with the owner's investment. The difference mainly lies in whether the economic benefits obtained come from operating activities.

We argue that, due to various reasons, the revenue in China's current practice is not consistent with the concept of revenue. Revenue refers to the total inflow of economic benefits formed in the daily operating activities of enterprise, which will lead to the increase of owners' equity. From the perspective of accounting practice, revenue mainly includes four aspects: firstly, the inflow of economic benefits generated by the production and operation activities of enterprise such as selling products and providing services; secondly, the inflow of economic benefits arising from the production and operation activities such as sales of products and provision of services by enterprise (i.e., in-price tax); thirdly, the inflow of unearned economic benefits arising from the enterprise's production and operation activities such as selling products and providing services (i.e., bad debt loss); fourthly, the preferential discount given to the buyer to recover the payment as soon as possible (i.e., cash discount). The above four parts are included in the accounting revenue account when the revenue is recognized. However, in addition to the first part, the latter three parts should not be recognized as revenue, because they do not lead to the increase of owners' equity and are not really realized. The essence of the deduction of revenue is different from that of expenses. Only by correctly distinguishing the deduction items of expenses and revenue can the users of financial statements obtain the real useful information.

2.1.1. The First Limitation: In-Price Tax Transferred to the Government. Theoretically speaking, revenue refers to the total inflow of economic benefits formed in the daily operating activities of enterprise, which will lead to the increase of owners' equity and have nothing to do with the capital invested by owners. However, part of the current revenue is not completely consistent with the theoretical definition. This is because the current revenue contains a certain proportion of in-price tax, which means excise tax, urban maintenance and construction tax, and education surcharges. From the basic attributes, in-price tax has the nature of "tax," which needs to be handed over to the tax department in a mandatory, free, and timely manner. It is the inflow of economic benefits accompanied by the production 
and operation activities of enterprise such as selling products and providing services. Although this part of the in-price tax flows into the enterprise together with the economic benefits generated by the enterprise's production and operation activities such as selling products and providing services, because the ownership of this part of in-price tax belongs to the government in essence, it will not increase the owner's equity of the enterprise and cannot be used to make up for the costs. No matter whether the enterprise is profitable or not, as long as the taxable behavior of selling goods and providing services occurs, it needs to pay the tax payable to the government in time.

Some scholars and regulations have proposed that the revenue should not include in-price tax. The nature of tax is different from that of expenses. Expenses are incurred to obtain revenue, and tax payment is the legal obligation of enterprise. Therefore, the tax payment of enterprise does not conform to the matching principle and should not be included in the process of determining profits and losses $[9,10]$. The MFPRC (Ministry of Finance of the People's Republic of China) issued the Accounting System for Enterprise on December 9, 2000, which stipulates in Article 84 the following: "Revenue refers to the total inflow of economic interests generated by enterprise in their daily activities such as selling commodities, providing services and transferring the right to the use of assets, including revenue from main business and revenue from other business. Revenue does not include money collected on behalf of third parties or customers". On May 9, 2016, FASB issued a new revenue standard to update "customer contract revenue (topic 606)." In the five-step revenue recognition model of the new revenue standard, the third step requires enterprise to determine the transaction price of the contract. Transaction price refers to the amount that an enterprise is expected to have the right to receive due to the transfer of goods or the provision of services to customers, excluding the money collected on behalf of a third party (such as certain sales taxes). At the same time, it is allowed that the transaction price does not include the payment collected on behalf of the third party as an accounting policy choice.

This paper holds that the essence of the in-price tax included in the current revenue is the same as that of the valueadded tax (VAT) calculated outside the price. Both of them are the taxes that the enterprise obtains from customers through the pricing mechanism and then transfers to the government. Although the corresponding economic benefits are collected simultaneously by the enterprise when selling products and providing services, they will not form the equity of the enterprise. The enterprise cannot use them to make up for the costs, let alone increase the owner's equity, so they should not be included in the category of revenue. The government is an uninvited third party. The collection of turnover tax is a direct participation in the distribution in the process of enterprise sales. The corresponding in-price tax with the nature of circulation, such as the excise tax, urban maintenance and construction tax, and education surcharges, has tax obligation when the revenue is realized. Because the turnover tax is transferable, this part of the in-price tax with the nature of circulation is essentially the tax collected by the enterprise from the customers on behalf of the government in the past transactions. When it comes into being, the ownership belongs to the government, which forms a current obligation for the enterprise to repay in the future. In order to reflect the nature of the in-price tax, the enterprise should recognize it as a liability. In the current accounting treatment, enterprises usually take this part of the tax collected as a part of the revenue first and then as a part of the expenses to be deducted from the revenue, resulting in the virtual increase of the revenue and expenses at the same time. According to the basic principle of matching revenue and expenses, the result of matching the revenue with the expenses incurred to obtain the revenue should be the business results of the enterprise, but the in-price tax is regarded as both the revenue and the expenses. The final matching result is zero, which obviously losses the significance of matching [13-9]. Although it does not affect the calculation of net profit, it causes the gross profit margin to be overestimated, which makes it difficult to accurately reflect the profitability of basic business. Therefore, the in-price tax included in the current revenue cannot be used to cover costs or to increase the owner's equity. In addition, the in-price tax is not in line with the matching principle. As a result, the in-price tax in the current revenue leads to the overestimation of the revenue, which is the first limitation of the current revenue.

\subsubsection{The Second Limitation: Bad Debt Loss. Bad debt loss} mainly refers to the part of the revenue which has been recognized by the enterprise but cannot be recovered finally. The recognized revenue, especially in the case of credit sales, usually cannot recover all the credit sales funds. Usually, there is a certain degree of bad debt loss. In essence, bad debt loss is the inflow of unearned economic benefits caused by the production and operation of enterprise such as selling products and providing services. The economic benefits corresponding to bad debt loss do not flow into the enterprise finally. The inflow of economic benefits and the increase of owners' equity are the basic conditions for the recognition of revenue. Since the bad debt loss fails to flow into the enterprise in the form of economic benefits, it cannot be regarded as a part of the revenue. Some scholars have pointed out that bad debt loss should be regarded as an offset item of revenue rather than expenses item. Hendrikson [9] pointed out that the bad debt loss is traditionally treated as expenses, but it was more reasonable to classify it as offsets of revenue than as expenses. This was because the bad debt loss did not mean the consumption of goods or services, but the reduction of the amount that can be collected by the exchange [9]. Only by correctly distinguishing the offsetting items and expenses items of revenue can the users of accounting information get the real useful information. Because the bad debt loss is the revenue that the enterprise fails to realize, rather than the expenses incurred to obtain the revenue, the bad debt loss is essentially the offset item of the revenue rather than the expenses item.

In the practice of accounting, the basic processing method of credit business is as follows: debit: accounts 
receivable, credit: revenue. The two completely correspond to each other. However, the accounts receivable listed in the balance sheet are listed according to the net amount of accounts receivable minus the provision for bad debts. At this time, accounts receivable and revenue do not correspond in quantity. From the phenomenon, it seems that the accounts receivable has not been collected, but the essence is that the revenue has not been realized. Since the revenue has not been realized, it is necessary to write down the revenue accordingly, instead of including the unrealized revenue into the expenses, which will lead to the overestimation of both revenue and expenses. From the perspective of revenueexpenses matching, it is similar to the in-price tax. In practice, the bad debt loss does not directly offset the revenue but is taken as revenue at first and then deducted from the revenue as an expenses. The matching result between the two is zero, which results in losing the significance of revenueexpenses matching. Although the final calculation of net profit is the same, but it leads to the overestimation of revenue. Under the same cost of sales, it will naturally lead to the overestimation of gross profit margin. Therefore, the bad debt loss does not directly offset the current revenue. It is recognized as an expense, which leads to overestimating the revenue. This is the second limitation of current revenue.

2.1.3. The Third Limitation: Cash Discount. Cash discount is a kind of preferential payment given by the seller to the buyer in order to encourage the buyer to speed up the payment. In the practice of accounting, the total price method of cash discount is the basic accounting treatment method: when cash discount occurs, it is included in financial expenses and accounts receivable, respectively. Theoretically, the cash discount under the total price method is the unrealized revenue of the seller or the transfer of the revenue to the buyer. Cash discount is an act of transferring revenue generated by the operating activities to the buyer, so the corresponding revenue has not been realized.

From the accounting treatment of cash discount by the total price method, it can be seen that the economic benefits corresponding to the part of cash discount do not flow into the enterprise in fact, which does not meet the recognition conditions of revenue. Because the cash discount is not directly deducted from the revenue, but included in the financial expenses, the actual revenue and financial expenses are overestimated at the same time. Similar to in-price tax and bad debt loss, although the final calculated net profit is the same, the revenue is overestimated, which leads to overestimating the gross profit margin when the cost of sales remains unchanged. Hendrikson [9] also pointed out that sales discounts are traditionally treated as expenses, but it was more reasonable to classify them as offsets of revenue than as expenses. Because sales discounts did not represent consumption of goods or services, a small portion of such discounts may represent monetary discounts or interest equivalent to waiting for the required costs without uncertainty. However, if such a discount was obtained, the net price represents the price of the goods; the discount should be the reduction in revenue rather than the cost of borrowing funds [9]. Therefore, the cash discount should not be included in the scope of revenue. Including cash discount within current revenue will lead to the overestimation of the gross profit margin.

Therefore, the cash discount does not directly offset the current revenue, but as an expenses deduction method from the current revenue, which leads to overestimating the revenue. This is the third limitation of current revenue. To sum up, in the current accounting practice of China, the inprice tax transferred by the enterprise to the government, the bad debt loss, and the cash discount are not considered as the unrealized revenue, but as the expenses incurred under the premise of the realized revenue. Therefore, these items do not directly offset the revenue but are included in the expenses, resulting in the virtual increase of the revenue, which leads to the overestimation of the gross profit margin.

2.2. Redefinition of Revenue. Therefore, we believe that the current revenue has the above three limitations, which means it includes the economic benefits that the enterprise has not really obtained, namely, in-price tax, bad debt loss, and cash discount. It is these limitations of the current revenue that lead to the unrealized revenue being regarded as the realized revenue, which leads to the overestimation of the revenue. Therefore, items such as in-price tax, bad debt loss, and cash discount should be eliminated from the current revenue, so that the revenue can truly become the inflow of economic benefits obtained by the enterprise through the sales of goods and the provision of services and really conform to the definition of revenue made by the Enterprise Accounting Standards. Only by eliminating the economic benefits that enterprise has not really obtained, such as in-price tax, bad debt loss, and cash discount, can the current revenue conform to the original meaning of revenue, so that the revenue realized by the enterprise can really be used to make up for the costs, create profits, and increase the owner's equity. Therefore, this paper classifies the revenue into current revenue and revenue. The revenue is the current revenue excluding in-price tax, bad debt loss, and cash discount.

Although the accounting scope of in-price tax subject changed in 2016, the property tax, land use tax, vehicle and ship tax, and stamp tax originally included in the management expenses subject were incorporated into the inprice tax subject, but the in-price taxes such as excise tax, urban maintenance and construction tax, and tax of educational surcharges were still the main components of the inprice tax. For the sake of simplification and convenient data acquisition, taxes and surcharges items are used to approximate the in-price tax. At the same time, when the bad debt loss and cash discount actually occur, the corresponding revenue may occur in the previous year's accounting period, so there is a problem of offsetting the current revenue or the previous period revenue. This paper believes that offsetting current revenue is a feasible and reasonable method. The reasons are as follows: (1) although offsetting the current revenue of previous periods has better matching effect theoretically, the accounting treatment of 
offsetting the current revenue of previous periods will eventually become the direct adjustment of the profits and losses of the previous years, which is difficult to see as the offset of the current revenue of the previous period; (2) if the business status and collection policy are stable, the bad debt loss and the cash discount between years should also be close to each other; (3) the processing method of directly offsetting the current revenue is convenient for data acquisition, which is relatively simple and feasible.

Based on the above analysis, the revenue can be redefined and expressed as follows:

$$
\begin{aligned}
\text { Revenue }= & \text { current revenue }- \text { in }- \text { price tax } \\
& - \text { bad debt loss }- \text { cash discount. }
\end{aligned}
$$

The following question is whether it is of practical significance and necessity to calculate the gross profit margin based on the revenue for the enterprise stakeholders, which means whether the gross profit margin calculated by the revenue caliber has higher information content than the gross profit margin calculated by the current revenue caliber, or whether the difference between the two has unique information content. Therefore, using the data of China's A-share listed companies from 2007 to 2019 and adopting the price model and the return model, we test whether the information content of the gross profit margin calculated by the revenue caliber is higher than that calculated by the current revenue caliber. In addition, after excluding the inprice tax and other items in the current revenue, the corresponding gross profit margin will also be reduced. Therefore, it is necessary to further test whether the reduced gross profit margin has unique information content, so as to demonstrate the practical significance and necessity of using the revenue caliber to calculate the gross profit margin. Based on the above analysis, the basic hypothesis of this paper is put forward:

H1: the gross profit margin calculated by the revenue caliber has higher information content than the gross profit margin calculated by the current revenue caliber.

\section{Research Design}

3.1. Data. The data source is China Stock Market \& Accounting Research Database (CSMAR). In the calculation of the future returns of the adjusted stock, the trading day before the annual report of listed companies is published to the trading day before the publication of the first quarterly report is selected as the calculation period. Therefore, it is necessary to exclude the listed companies for which the annual report and the quarterly report are published on the same day, and the listed companies with no trading day between the publication date of the annual report and the first quarterly report. At the same time, if some listed companies pay dividends during this period, it is easy to reduce the comparability between the stock prices of other listed companies and the future returns of adjusted stocks, and there are fewer listed companies paying dividends during this period. Therefore, the samples of listed companies that pay dividends between the date of annual report and the date of first quarter report are excluded. Other excluded samples include financial listed companies, ST listed companies, and data missing companies. The data period is 2007-2019, in which the period of calculating asset growth rate and GDP growth rate is 2007-2018; the period of stock price and adjusted future stock returns data is 2009-2019, because the annual report and first quarter report are generally published before the end of April of the next year in the reporting year; the data period of other variables is 2008-2018. Finally, 2906 listed companies and 16234 observations were obtained. In order to avoid the influence of extreme value, Winsor tailing is performed on the main continuous variables except stock price at the level of $1 \%$.

3.2. Methods. In the empirical test, we face three main challenges: (1) to choose price model or return model to test the information content of gross profit margin based on revenue and current revenue; (2) how to define the future stock price in the price model and the future stock returns in the return model; (3) how to determine the year when the data starts. In view of these three challenges, we make the following countermeasures: (1) Considering the advantages and disadvantages of price model and return model in the literature, we adopt both price model and return model to make the conclusion more robust. (2) Considering the special institutional environment in China, the quarterly report must be disclosed after the annual report, so there is a window period. We select the period after the disclosure of the annual report and before the disclosure of the first quarterly report as the calculation range of the future stock returns and determine the future stock price as the closing price of the stock on the trading day before the disclosure of the first quarterly report. (3) Considering that China began to implement the new accounting standards that converge to the international accounting standards on a large scale in 2007, 2007 is selected as the starting year of the data.

Generally, the information content of a specific accounting figure means that it can be transmitted to the stock price after it is published, which means it has value relevance. Ball and brown [10] first conducted an empirical study on the value relevance of accounting earnings. According to the actual accounting data and stock prices, it verified that accounting earnings had value relevance, which means it had unique information content [10]. Since then, a large number of studies have focused on whether accounting earnings have information content, and developed a variety of theoretical and empirical models, among which the empirical test model mainly included price model and return model. Kothari and Zimmerman [17] discussed the differences between the price model and the return model in detail on the basis of previous studies. They thought that the price model was more likely to produce heteroscedasticity in measurement, and the model setting was biased, but the deviation of the estimation coefficient was small. Therefore, they advocated using the price model and the return model at the same time, so as to make the test more effective [17]. Based on Fama and French's research in 2015, this paper 
constructs a price model and a return model to test the impact of revenue on the information content of gross profit margin [18].

The price model is shown in the following formulas:

$$
\ln \left(\text { Price }_{i, t+1}\right)=\alpha_{0}+\alpha_{1} \text { Gross_c }_{-} u_{i, t}+\alpha_{n} \text { Control }_{i, t}+\varepsilon_{i, t} \text {, }
$$

$$
\begin{aligned}
\ln \left(\text { Price }_{i, t+1}\right)= & \beta_{0}+\beta_{1} \text { Gross }_{i, t}+\beta_{n} \text { Control }_{i, t}+\delta_{i, t}, \\
\ln \left(\text { Price }_{i, t+1}\right)= & \gamma_{0}+\gamma_{1}\left(\text { Gross }_{-} c u_{i, t}-\text { Gross }_{i, t}\right) \\
& +\gamma_{n} \text { Control }_{i, t}+\theta_{i, t} .
\end{aligned}
$$

In (2)-(4), $\ln \left(\right.$ Price $\left._{i, t+1}\right)$ represents the logarithm of the closing price of the stock on the trading day before the publication of the first quarter report of the $i$-th listed company in the year $t+1$. According to Article 5 of "The Rules for Information Disclosure of Companies Offering Securities to the Public No. 13-Content and Format of Quarterly Reports" (revised in 2016) (Notice of China Securities Regulatory Commission [2016] No. 33), the disclosure time of quarterly report of the first quarter shall not be earlier than the annual report of the previous year. Therefore, there is a period between the annual report and the first quarter report of listed companies in China, which means the disclosure time of annual report is generally earlier than that of the first quarter report. Therefore, in order to avoid the influence of the quarterly report on the information of the annual report, the closing price (logarithm) of the stock on the trading day before the publication of the quarterly report is selected as the explained variable of the price model. Gross_ $\mathrm{Cu}_{i, t}$ refers to the gross profit margin of the $i$-th listed company calculated according to the current revenue caliber in the year $t$, and Gross ${ }_{i, t}$ refers to the gross profit margin of the $i$-th listed company calculated according to the revenue caliber in the year $t$.

According to the existing accounting information content research literature, combined with the research background of this paper, this paper determines the corresponding control variables. Gross_c $u_{-} y_{i, t}$ refers to whether the $i$-th listed company has a loss based on the gross profit calculated according to the current revenue caliber in the year $t$. Gross $y_{i, t}$ is whether the $i$-th listed company has a loss based on the gross profit calculated according to the revenue caliber in the year $t$. Asset ${ }_{i, t}$ is the total assets at the end of the year of the $i$-th listed company. Dividend ${ }_{i, t}$ is the cash dividend per share issued by the $i$-th listed company in the year $t . B_{-} m_{i, t}$ is the book-to-market ratio of the $i$-th listed company in year $t . \operatorname{Lev}_{i, t}$ is the year-end asset-liability ratio of the $i$-th listed company in the year $t$. Asgro ${ }_{i, t}$ is the growth rate of the total assets of the $i$-th listed company in the year $t$. Ret $m_{i, t+1}$ is the monthly average return of the stock of the $i$ th listed company from January to April in the year $t+1$. Change_ $m_{i, t+1}$ is the monthly average turnover rate of the $i$ th listed company from January to April in the year $t+1$. The reason why we choose the monthly average return rate and turnover rate from January to April as the control variables is that the China's A-share listed companies' annual report and the first quarter report are generally published between the beginning of January and the end of April of the next year. $\mathrm{Noe}_{i, t}$ refers to the nature of equity of the $i$-th listed company in the year $t$. As the stock market is greatly affected by macro-economy and monetary policy, the GDP growth rate in the year $t\left(G d p_{t}\right)$, the money supply in the year $t\left(M 2_{t}\right)$, and the Purchasing Managers' Index in the year $t\left(P m i_{t}\right)$ are controlled at the same time. We focus on coefficients $\alpha_{1}, \beta_{1}$, and $\gamma_{1}$. First of all, if $\alpha_{1}$ is significant, this means that the gross profit margin calculated by the current revenue caliber has value relevance, which means it has unique information content; if $\beta_{1}$ is significant, this means that the gross profit margin calculated by revenue caliber also has unique information content; if $\gamma_{1}$ is significant, this means that the difference between the gross profit margin calculated by the current revenue caliber and the gross profit margin calculated by the revenue caliber has a unique information content, which means it is meaningful to calculate the gross profit margin using the revenue caliber. Secondly, because the gross profit margin is a positive indicator to measure enterprise performance, which means the higher the gross profit margin, the better the enterprise performance, it is expected that $\alpha_{1}$ and $\beta_{1}$ are significantly positive, which means that the higher the gross profit margin, the better the enterprise performance, and then the higher the stock price. At the same time, because the gross profit margin calculated by using the revenue caliber eliminates the items that do not meet the definition of revenue in the current revenue, it also squeezes out the "moisture" in the gross profit margin, thus improving the information content of the gross profit margin to a certain extent, so the estimated coefficient $\beta_{1}$ is expected to be greater than the coefficient $\alpha_{1}$. This means that the information content of gross profit margin calculated by revenue caliber is higher than that calculated by current revenue caliber. Finally, (Gross_c $\mathcal{u}_{i, t}-$ Gross $_{i, t}$ ) indicates the extent to which the gross profit margin is overestimated. The higher the gross profit margin is overestimated, the worse the actual performance of the enterprise is, and the lower the corresponding stock price is. Therefore, the coefficient $\gamma_{1}$ is expected to be significantly negative.

The return model is shown in the following equation:

$$
\begin{aligned}
\text { Ret_adj }_{i, t+1}= & \alpha_{0}+\alpha_{1} \text { Gross_cu }_{i, t}+\alpha_{n} \text { Control }_{i, t}+\varepsilon_{i, t}, \\
\text { Ret_adj }_{i, t+1}= & \beta_{0}+\beta_{1} \text { Gross }_{i, t}+\beta_{n} \text { Control }_{i, t}+\delta_{i, t}, \\
\text { Ret_adj }_{i, t+1}= & \gamma_{0}+\gamma_{1}\left(\text { Gross_cu }_{i, t}-\text { Gross }_{i, t}\right) \\
& +\gamma_{n} \text { Control }_{i, t}+\theta_{i, t} .
\end{aligned}
$$

In (5)-(7), Ret_adj $j_{i, t+1}$ is under the industry adjusted stock holding return of the $i$-th listed company from the publication of the annual report to the first quarterly report in the $t+1$ year. In order to avoid the superimposed influence of information disclosure in the first quarter report and find out a cleaner stock return, the period from the publication of the annual report of listed companies to that before the publication of the first quarter report is selected as the calculation period of future stock returns. At the same time, in order to avoid the influence of industry factors, the 
industry adjusted stock holding return is obtained by deducting the industry average value from the stock holding return of the listed company during the period, which is used as the proxy variable of future stock return (Ret_adj $\left.j_{i, t+1}\right)$. The explanatory variable of the return model is the same as that of the price model, and the verification idea is the same. The difference is that the explained variable is changed from the stock price to the adjusted future return of the stock. Therefore, the same attention is paid to whether the coefficients $\alpha_{1}$ and $\beta_{1}$ are significantly positive, whether the coefficient $\beta_{1}$ increases relative to $\alpha_{1}$, and whether the coefficient $\gamma_{1}$ is significantly negative. The detailed definitions are presented in Table 1 .

\section{Results and Discussions}

4.1. Summary Statistics. The results of descriptive statistics show that the average closing price of listed companies on the trading day before the publication of the first quarter report is 14.913 yuan, the minimum value is 2.940 yuan, and the maximum value is 63.220 yuan; the average value of the adjusted future stock return from the publication of the annual report to the first quarter report of listed companies is $0.7 \%$, the minimum value is $-21.6 \%$, and the maximum value is $40.5 \%$. The average value of gross profit margin calculated by the current revenue caliber of listed companies is $27.6 \%$, and the average value of gross profit margin calculated by revenue caliber is $26.1 \%$. The former is 1.5 percentage points higher than the latter, as shown in Table 2.

4.2. Correlation Analysis. Before the regression analysis, the correlation analysis of the main variables was carried out. First of all, we investigate the correlation coefficient between the gross profit margin calculated by the current revenue caliber, the gross profit margin calculated by the revenue caliber, and the stock price, which means the main variable of the price model. From the Pearson correlation coefficient, the correlation coefficient between the gross profit margin and the stock price (logarithm) calculated by the current revenue caliber is 0.304 , which is significant at the $1 \%$ level; the correlation coefficient between the gross profit margin and the stock price calculated by the revenue caliber is 0.325 , which is higher than the correlation coefficient under the current revenue caliber, and it is also significant at the $1 \%$ level. The correlation coefficient between the difference between the gross profit margin calculated by the current revenue caliber and the gross profit margin calculated by the revenue caliber, and the stock price is -0.171 , which is significant at the $1 \%$ level. From the Spearman correlation coefficient, the correlation coefficient between the gross profit margin calculated by the current revenue caliber and the stock price is 0.302 , which is significant at the level of $1 \%$; the correlation coefficient between the gross profit margin calculated by the revenue caliber and the stock price is 0.323 , which is also higher than the correlation coefficient under the current revenue caliber, and it is significant at the $1 \%$ level. The correlation coefficient between the difference between the gross profit margin calculated by the current revenue caliber and the gross profit margin calculated by the revenue caliber, and the stock price is -0.139 , which is significant at the level of $1 \%$, as shown in Table 3 .

Secondly, we investigate the correlation coefficient between the gross profit margin calculated by the current revenue caliber, the gross profit margin calculated by the revenue caliber, and the adjusted future stock return, which means the main variable of the return model. From the Pearson correlation coefficient, the correlation coefficient between the gross profit margin calculated by the current revenue caliber and the adjusted future stock return is 0.012 , which is not significant; the correlation coefficient between the gross profit margin calculated by the revenue caliber and the adjusted future stock return is 0.016 , which is higher than the correlation coefficient under the current revenue caliber, and the correlation coefficient is significant at the 5\% level. The correlation coefficient between the difference between the gross profit margin calculated by the current revenue caliber and the gross profit margin calculated by the revenue caliber, and the adjusted future stock return is -0.021 , which is significant at the $1 \%$ level. From the Spearman correlation coefficient, the correlation coefficient between the gross profit margin calculated by the current revenue caliber and the adjusted future stock return is 0.019 , which is significant at the level of $5 \%$; the correlation coefficient between the gross profit margin calculated by the revenue caliber and the adjusted future stock return is 0.023 , which is also higher than the correlation coefficient under the current revenue caliber. The correlation coefficient between the difference between the gross profit margin calculated by the current revenue caliber and the revenue caliber, and the adjusted future stock return is -0.028 , which is significant at the level of $1 \%$, as shown in Table 3 .

4.3. Regression Results. Based on the results of Pearson correlation coefficient and Spearman correlation coefficient, it can be found that the correlation between gross profit margin calculated by revenue caliber is higher than that calculated by current revenue caliber, and the difference between gross profit margin calculated by current revenue caliber and revenue caliber has a significant negative correlation with both stock price and adjusted future stock return. This result shows that the information content of gross profit margin calculated by revenue caliber is higher than that calculated by current revenue caliber. The higher the degree of gross profit margin being overestimated, the lower the corresponding stock price and the adjusted future stock return, which means the information content of gross profit margin is improved by adopting revenue caliber.

Furthermore, regression analysis is used to investigate the influence of revenue on the information content of gross profit margin. From the perspective of the price model, the coefficient of gross profit margin calculated by the current revenue caliber is 0.578 , which is significant at the level of $1 \%$. The coefficient of gross profit margin calculated by the revenue caliber is 0.590 , which is higher than that calculated by the current revenue caliber, and is significant at the level of $1 \%$. The coefficient difference 
TABLE 1: Variable definitions.

\begin{tabular}{|c|c|c|c|}
\hline Variable type & Name & Code & Variable description \\
\hline \multirow{4}{*}{$\begin{array}{l}\text { Explained } \\
\text { variable }\end{array}$} & Stock price & Price & $\begin{array}{c}\text { The closing price of a stock on the trading day prior to the release of } \\
\text { the first quarterly report }\end{array}$ \\
\hline & Future stock returns & Ret & $\begin{array}{c}\text { The stock holding return from the publication of the annual report } \\
\text { to the first quarterly report }\end{array}$ \\
\hline & Future stock returns of industry & Ret_sic & $\begin{array}{c}\text { Industry average (manufacturing subdivided into secondary } \\
\text { industries) }\end{array}$ \\
\hline & Adjusted future stock returns & Ret_adj & Ret - Ret_sic \\
\hline \multirow{2}{*}{$\begin{array}{l}\text { Explanatory } \\
\text { variables }\end{array}$} & $\begin{array}{l}\text { Gross profit margin calculated by } \\
\text { current revenue caliber }\end{array}$ & Gross_cu & (Current revenue - cost of sales)/current revenue $* 100 \%$ \\
\hline & $\begin{array}{l}\text { Gross profit margin calculated by } \\
\text { revenue caliber }\end{array}$ & Gross & $($ Revenue - cost of sales)/revenue $* 100 \%$ \\
\hline \multirow{12}{*}{ Control variable } & Profitable or not & Gross_cu_y & $\begin{array}{l}\text { Whether the company has a loss based on the gross profit calculated } \\
\text { according to the current revenue caliber } \\
\text { Whether the company has a loss based on the gross profit calculated } \\
\text { according to the revenue caliber }\end{array}$ \\
\hline & Scale & Asset & Logarithm of total assets at the end of the year \\
\hline & Book-to-market rate & B_m & Year-end net assets/year-end market value \\
\hline & Cash dividend & Divide & Cash dividends per share \\
\hline & Asset liability rate & Lev & Year-end total liabilities/year-end total assets \\
\hline & Asset growth rate & Asgro & Year-end total assets/last year-end total assets -1 \\
\hline & Average rate of return & Ret_m & Monthly average stock return from January to April \\
\hline & Average turnover rate & Change_m & Monthly average turnover rate of stocks from January to April \\
\hline & Nature of equity & Noe & Whether it is a state-owned enterprise or not \\
\hline & GDP growth rate & Gdp & GDP growth rate over the last year \\
\hline & Money supply & M2 & Money supply \\
\hline & Economic prosperity & Pmi & Manufacturing Purchasing Managers' Index for December \\
\hline
\end{tabular}

TABle 2: Descriptive statistics of main variables.

\begin{tabular}{lccccc}
\hline Variable & Sample size & Mean & Minimum & Maximum & Standard deviation \\
\hline Price & 16234 & 14.913 & 2.940 & 63.220 & 11.208 \\
Ret_adj & 16234 & 0.007 & -0.216 & 0.405 & 0.105 \\
Gross_cu & 16234 & 0.276 & 0.000 & 0.814 & 0.170 \\
Gross & 16234 & 0.261 & -0.039 & 0.819 & 0.169 \\
Asset & 16234 & 22.122 & 15.418 & 28.509 & 1.364 \\
B_m & 16234 & 1.005 & 0.094 & 5.433 & 0.973 \\
Divide & 16234 & 0.111 & 0.000 & 0.800 & 0.150 \\
Lev & 16234 & 0.449 & 0.052 & 0.927 & 0.211 \\
Asgro & 16234 & 0.204 & -0.276 & 3.214 & 0.439 \\
Ret_m & 16234 & 0.027 & -0.168 & 0.571 & 0.073 \\
Change_m & 16234 & 0.487 & 0.000 & 268.575 & 2.156 \\
\hline
\end{tabular}

TABLE 3: Correlation analysis of main variables. Definition of variables is given in Table 1.

\begin{tabular}{|c|c|c|c|c|c|}
\hline & $\ln$ (price) & Ret_adj & Gross_cu & Gross & Gross_cu-gross \\
\hline $\ln$ (price) & 1 & $0.076^{\text {*** }}$ & $0.302^{\text {*** }}$ & $0.323^{* * *}$ & $-0.139^{* * *}$ \\
\hline Ret_adj & $0.094^{* * *}$ & 1 & $0.019^{* *}$ & $0.023^{* * *}$ & $-0.028^{* * *}$ \\
\hline Gross_cu & $0.304^{\text {*** }}$ & 0.012 & 1 & $0.984^{\text {*** }}$ & $0.228^{\text {*** }}$ \\
\hline Gross & $0.325^{* * *}$ & $0.016^{* *}$ & $0.981^{* * *}$ & 1 & $0.129^{* * *}$ \\
\hline Gross_cu-gross & $-0.171^{\text {**** }}$ & $-0.021^{* * *}$ & $0.123^{\text {*** }}$ & $-0.016^{* *}$ & 1 \\
\hline
\end{tabular}

${ }^{* * *},{ }^{* *}$, and $*$ indicate $1 \%, 5 \%$, and $10 \%$ significance, respectively. Pearson correlation coefficient is at the bottom left, and Spearman correlation coefficient is at the upper right.

between the two ( $P$ value) is 0.086 , which indicates that the coefficient of the gross profit margin based on the revenue caliber is significantly higher than that based on the current revenue caliber. Therefore, the information content of the gross profit margin calculated by the revenue caliber is higher than that calculated by the 
current revenue caliber. The coefficient of the difference between the gross profit margin calculated by the current revenue caliber and the gross profit margin calculated by the revenue caliber is -1.961 , which is significant at the level of $1 \%$. The higher the degree of overestimation, the lower the corresponding stock price, which further proves that the gross profit margin calculated by the current revenue caliber distorts the actual basic business profitability of the enterprise, and the information content of the gross profit margin is significantly improved by using the revenue caliber.

According to the return model, the coefficient of gross profit margin calculated by the current revenue caliber is 0.012 , which is significant at the level of $5 \%$. The coefficient of gross profit margin calculated by the revenue caliber is 0.013 , which is higher than the coefficient calculated by the current revenue caliber, and is also significant at the level of 5\%. The coefficient difference between the two ( $P$ value) is 0532 . The coefficient of the difference between the gross profit margin calculated by the current revenue caliber and the gross profit margin calculated by the revenue caliber is -0.085 , which is significant at the level of $10 \%$. This shows that the higher the gross profit margin is overestimated, the lower the adjusted future stock return is. That is to say, the gross profit margin calculated by the current revenue caliber distorts the actual basic business profitability of the enterprise, and the information content of the gross profit margin is improved by using the revenue caliber. Although in the return model there is no significant difference between the gross profit margin coefficient calculated by the current revenue caliber and the gross profit margin coefficient calculated by the revenue caliber, the coefficient of the difference between the two "gross profit margins" is significantly negatively correlated with the adjusted future stock return, which also shows that the gross profit margin calculated by the current revenue caliber distorts the actual basic business profitability of the enterprise to a certain extent. That is to say, it is of practical significance and necessity to calculate gross profit margin under the revenue caliber.

Based on the empirical results of the price model and the return model, we can draw the following basic conclusions: the information content of the gross profit margin is improved after the in-price tax and other unrealized items in the current revenue are removed, which means the information content of the gross profit margin is improved by using the revenue caliber, as shown in Table 4.

4.4. Further Discussion. On the basis of the above analysis, we try to answer the question of how high is the gross profit margin of China's listed companies. Taking the gross profit margin of listed companies in 2018 as the analysis object, the samples of ST listed companies are excluded because their operating conditions may be abnormal. Due to the particularity of the financial industry and the less application of gross profit margin, the samples of financial listed companies are excluded. The industry classification standard adopts the industry standard revised by China Securities Regulatory Commission in 2012, and the data source is
CSMAR database. Finally, 3281 listed companies in 17 industries are obtained. The gross profit margins calculated by the current revenue caliber and revenue caliber of different industries and the whole industry are calculated, respectively.

As a whole, in 2018, the total current revenue of the sample listed companies was 11628.318 billion yuan, the total cost of sales was 9092.284 billion yuan, and the corresponding gross profit was 2536.034 billion yuan. The total in-price tax was 146.304 billion yuan, and the total bad debt loss was 52.901 billion yuan. If we make the calculation according to the revenue caliber, which means the current revenue minus in-price tax and bad debt loss, the total revenue is 11429.113 billion yuan, and the corresponding gross profit is 2336.829 billion yuan, which means that the gross profit is reduced by 1992.205 billion yuan compared with the current revenue. From the above analysis, it can be seen that the gross profit calculated by the current revenue caliber is higher than that calculated by the revenue caliber. Based on the above data, it can be calculated that in 2018 the gross profit margin of China's listed companies calculated according to the current revenue caliber was $21.81 \%$ and that the gross profit margin calculated by revenue caliber was $20.45 \%$, with a difference of 1.36 percentage points. That is to say, in 2018, the gross profit margin of China's listed companies was overestimated by 1.36 percentage points under the influence of in-price tax and bad debt loss. If the cash discount has been considered, the overestimation will exceed 1.36 percentage points.

From the perspective of different industries, the gross profit margin of manufacturing listed companies based on the current revenue caliber is $22.47 \%$, and the gross profit margin calculated by revenue caliber is $21.31 \%$, which means that the gross profit margin of manufacturing listed companies as a whole is overestimated by 1.16 percentage points. The industry with the highest degree of overestimation of gross profit margin is comprehensive industry. The gross profit margin of the industry as a whole is $31.05 \%$ based on the current revenue caliber and $27.12 \%$ based on the revenue caliber. The gross profit margin is overestimated by 3.93 percentage points. The industry with the lowest degree of overestimation of gross profit margin is accommodation industry. The gross profit margin of the industry as a whole is $78.36 \%$ based on the current revenue caliber and $78.06 \%$ based on the revenue caliber. The gross profit margin is overestimated by $0.3 \%$, as shown in Table 5 .

Table 5 presents the overestimation of gross profit margin of listed companies by industry in 2018. The unit is billion yuan. The industry classification standard revised by CSRC in 2012 is adopted. The current gross profit margin refers to the gross profit margin calculated according to the current revenue caliber. The calculation method is as follows: (current revenue-cost of sales)/current revenue. Gross profit margin refers to the gross profit margin calculated according to the caliber of revenue. The calculation method is: ((current revenue - in-price tax - bad debt loss) - cost of sales)/(current revenue - in-price tax - bad debt loss); the inprice tax is approximately replaced by taxes and surcharges. As the listed companies generally do not disclose the cash 
TABLE 4: Regression results.

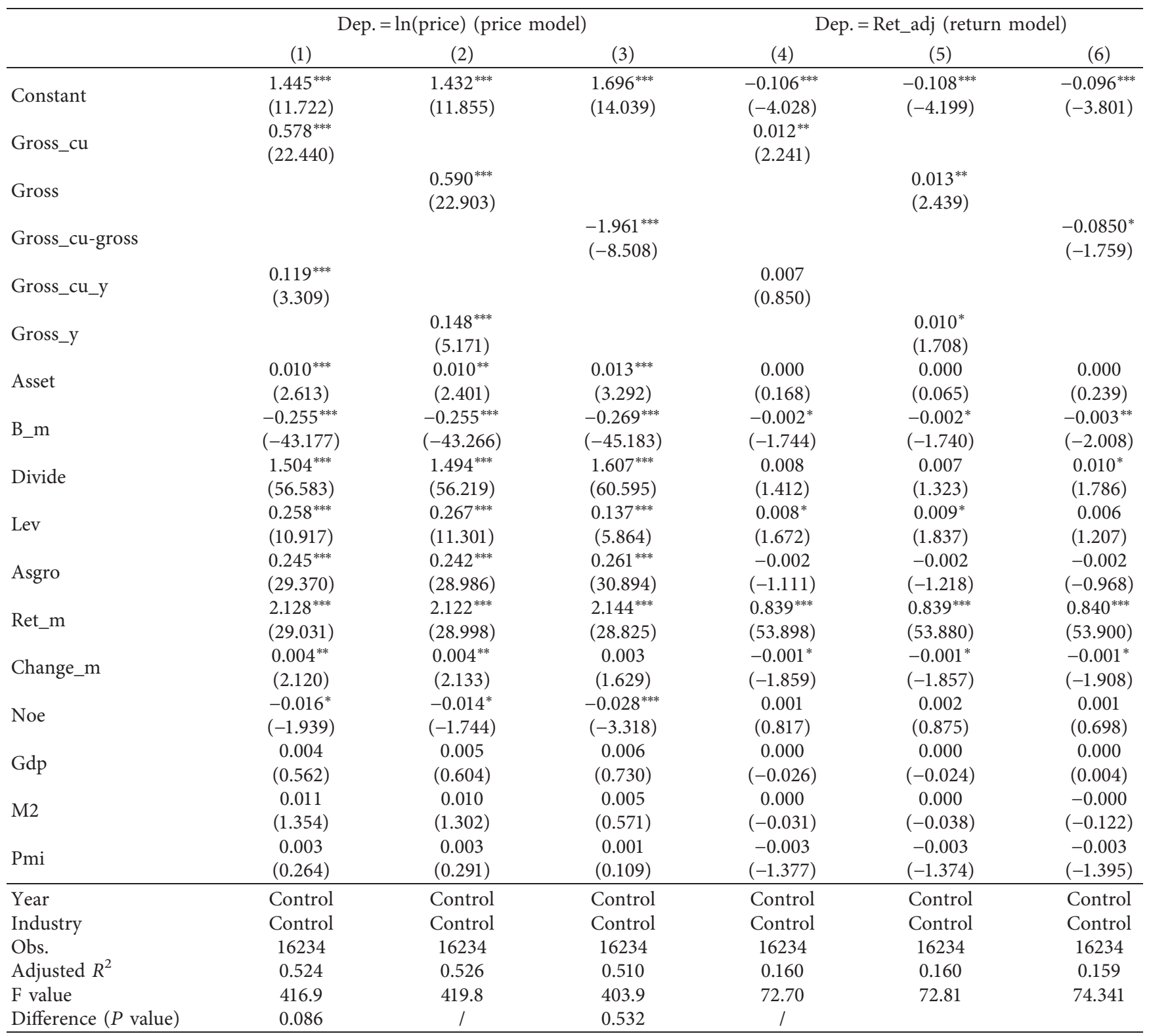

$* * *, * *$, and $*$ indicate $1 \%, 5 \%$, and $10 \%$ significance, respectively.

discount, we cannot exclude the cash discount when we calculate the gross profit margin in the revenue caliber.

Gross profit margin is the most widely used performance evaluation index in practice and academia. The existing research on gross profit and gross profit margin mainly focuses on enterprise performance evaluation and prediction. The research of enterprise performance evaluation usually takes gross profit and gross profit margin as the basic indicators to reflect enterprise performance, studies the factors affecting enterprise performance, and explores new enterprise performance evaluation methods on this basis [4, 19-30]. The research on enterprise performance prediction also takes gross profit and gross profit margin as the indicators to reflect the basic profitability of enterprises. On this basis, it studies how to better predict the future performance level of enterprises [3, 31-41]. Therefore, in the literature context of enterprise performance evaluation and enterprise performance prediction, gross profit and gross profit margin are usually used as indicators to evaluate the basic performance level of enterprises, and less attention is paid to the possible problems of the indicator itself. This paper is devoted to analyzing the defects and improvement of the gross profit margin itself, so the research conclusion on gross profit margin overestimation of Chinese listed companies complements and perfects the relevant research on enterprise performance evaluation and prediction of gross profit margin. 
TABLe 5: Overestimation of gross profit margin of listed companies by industry in 2018.

\begin{tabular}{|c|c|c|c|c|c|c|c|c|}
\hline Industry & $\mathrm{N}$ & $\begin{array}{l}\text { Current } \\
\text { revenue }\end{array}$ & $\begin{array}{l}\text { Cost of } \\
\text { sales }\end{array}$ & $\begin{array}{l}\text { In-price } \\
\text { tax }\end{array}$ & $\begin{array}{l}\text { Bad debt } \\
\text { loss }\end{array}$ & $\begin{array}{l}\text { Current gross profit } \\
\text { margin }(\%)\end{array}$ & $\begin{array}{l}\text { Gross profit } \\
\text { margin }(\%)\end{array}$ & $\begin{array}{l}\text { Difference } \\
(\%)\end{array}$ \\
\hline Education & 3 & 4.64 & 3.105 & 0.03 & 0.007 & 33.08 & 32.54 & 0.54 \\
\hline Accommodation & 9 & 21.892 & 4.738 & 0.274 & 0.018 & 78.36 & 78.06 & 0.29 \\
\hline Health & 9 & 17.935 & 10.684 & 0.053 & 0.128 & 40.43 & 39.82 & 0.61 \\
\hline Comprehensive & 23 & 19.078 & 13.154 & 0.572 & 0.458 & 31.05 & 27.12 & 3.93 \\
\hline Scientific & 40 & 34.447 & 24.035 & 0.215 & 1.011 & 30.23 & 27.65 & 2.57 \\
\hline Environment & 41 & 46.448 & 30.087 & 0.599 & 0.725 & 35.22 & 33.32 & 1.90 \\
\hline Agriculture & 44 & 91.418 & 76.239 & 0.339 & 0.766 & 16.60 & 15.58 & 1.02 \\
\hline Lease & 46 & 210.139 & 176.436 & 1.233 & 1.601 & 16.04 & 14.89 & 1.15 \\
\hline Culture & 53 & 94.507 & 64.373 & 0.843 & 1.985 & 31.89 & 29.78 & 2.10 \\
\hline Mining & 75 & 625.004 & 493.543 & 13.924 & 1.541 & 21.03 & 19.03 & 2.00 \\
\hline Transportation & 90 & 526.725 & 427.949 & 2.72 & 0.979 & 18.75 & 18.18 & 0.57 \\
\hline Construction & 99 & 642.845 & 542.393 & 7.828 & 3.7 & 15.63 & 14.09 & 1.54 \\
\hline Electric & 103 & 536.333 & 417.755 & 7.535 & 0.967 & 22.11 & 20.85 & 1.25 \\
\hline Real estate & 124 & 755.614 & 517.299 & 35.411 & 2.668 & 31.54 & 27.91 & 3.63 \\
\hline Wholesale & 161 & 1371.223 & 1171.261 & 8.803 & 2.601 & 14.58 & 13.87 & 0.72 \\
\hline Software & 241 & 353.6 & 252.883 & 2.433 & 5.18 & 28.48 & 26.91 & 1.57 \\
\hline Manufacturing & 2120 & 6276.47 & 4866.35 & 63.492 & 28.566 & 22.47 & 21.31 & 1.15 \\
\hline Whole industry & 3281 & 11628.318 & 9092.284 & 146.304 & 52.901 & 21.81 & 20.45 & 1.36 \\
\hline
\end{tabular}

\section{Conclusion}

The calculation of gross profit margin involves two elements: revenue and cost of sales. There is no controversy over the definition of cost of sales in academia, which means the production cost of manufacturing enterprise (i.e., materials, labor, and manufacturing overhead) or the purchase cost of commodity circulation enterprises [42]. However, there are different understandings of the concept of revenue $[43,44]$. The main reason is that the current revenue includes the in-price tax, bad debt loss, and cash discount. The in-price tax will be transferred to the government after the sale finishes. The bad debt loss is the sales fund that the enterprise fails to receive actually. The cash discount is the enterprise's concession to the sales amount receivable from customers. None of the three items is actually conducted, which means that they cannot bring economic benefits for the firms, and they can neither be used to cover costs nor increase the owners' equity [45-47]. Because the revenue includes the above three items, the gross profit margin of enterprise is overestimated, and then the real basic business profitability of enterprise cannot be reflected.

The revenue should reflect the economic benefits obtained from customers by selling goods and services. These economic benefits can increase the owner's equity but have nothing to do with the capital invested by the owners. However, the current revenue actually includes some unrealized items such as the in-price tax, bad debt loss, and cash discount. In essence, the in-price tax included in the current revenue is similar to the value-added tax calculated outside the price, both of which are benefit distribution participated by the government in the circulation link. Enterprise passes on the in-price tax with the nature of circulation to customers through the pricing mechanism, which is actually collecting taxes from downstream customers on behalf of the government. Therefore, this part of the in-price tax included in the current revenue has not been realized, nor is it the price paid by the enterprise to obtain revenue. Therefore, it does not conform to the basic definition of revenue and the basic connotation of expenses. The economic benefits corresponding to the bad debt loss and cash discount failed to flow into the enterprise finally, which also could not lead to the increase of owner's equity, so they do not conform to the definition of revenue in Enterprise Accounting Standards. Therefore, the current revenue which includes in-price tax, bad debt loss, and cash discount cannot be regarded as the revenue of the enterprise, let alone using the current revenue to calculate the gross profit margin. If we turn a blind eye to the above three limitations existing in the current revenue, this will inevitably lead to the overestimation of the gross profit margin, then lead to the overestimation of the basic business profitability of the enterprise, and finally mislead the enterprise stakeholders. In order to improve the accuracy and the scientific of the gross profit margin index and give full play to its role, the in-price tax, bad debt loss, and cash discount should be excluded from the current revenue when calculating the gross profit margin. In other words, the gross profit margin calculated under the revenue caliber can reflect the profitability of the basic business of the enterprise accurately.

In this paper, we propose to eliminate in-price tax, bad debt loss, and cash discount from the current revenue, so as to obtain the revenue, and then calculate the gross profit margin. Based on the existing literature and theory, using the data of China's listed companies from 2007 to 2019 and using the methods of theoretical analysis, empirical test, and actual measurement, this paper explores the theoretical root and practical countermeasures of overestimation of gross profit margin caused by the limitations of current revenue. The regression results show that whether the price model or return model is used, the information content of gross profit margin calculated based on revenue caliber is higher than that of current revenue caliber. This result supports and is in line with the research hypothesis $\mathrm{H} 1$. 
The conclusions are as follows: (1) There are three unrealized items in the current revenue, namely, the in-price tax transferred to the government, the bad debt loss, and the cash discount transferred to customers. Consequently, in the accounting practice, the current revenue cannot be used to make up for the expenses, nor can it increase the owner's equity. At the accounting theory level, the current revenue does not fully conform to the definition of revenue, resulting in the conflict between the revenue caliber in the profit statement framework and the revenue concept defined by the basic standards. Therefore, the gross profit margin calculated by the current revenue will inevitably lead to the overestimation of the gross profit margin. In order to get the revenue, it is necessary to eliminate the in-price tax, bad debt loss, and cash discount from the current revenue and calculate the gross profit margin based on the revenue to reflect the actual basic business profitability of the enterprise. (2) The empirical test shows that compared with the gross profit margin based on the current revenue, the gross profit margin based on the revenue has higher information content. (3) In 2018, the gross profit margin of China's listed companies calculated according to the current revenue caliber was $21.81 \%$, and the gross profit margin based on the revenue caliber was $20.45 \%$, which means that the gross profit margin was overestimated by 1.36 percentage points due to the limitations of current revenue.

In a word, the current revenue includes the economic benefits that the enterprise has not really obtained, such as the in-price tax, bad debt loss, and cash discount, which leads to the overestimation of the gross profit margin. It is suggested that the gross profit margin should be calculated by the revenue excluding in-price tax, bad debt loss, and cash discount from the current revenue, so as to eliminate the limitations of the current revenue and give better play to the important role of the gross profit margin index in evaluating the profitability of the basic business of enterprise.

\section{Data Availability}

The data source is China Stock Market \& Accounting Research Database (CSMAR), https://www.gtarsc.com/.

\section{Conflicts of Interest}

The authors declare that they have no conflicts of interest.

\section{Authors' Contributions}

Fulei Shi developed the idea of the study, Bingbing Huang built the model and wrote the original draft of the manuscript, and Chuanqi $\mathrm{Wu}$ and Liang Jin revised the manuscript.

\section{References}

[1] D. H. Lee, "Cost-benefit analysis, LCOE and evaluation of financial feasibility of full commercialization of biohydrogen," International Journal of Hydrogen Energy, vol. 41, no. 7, pp. 4347-4357, 2016.

[2] T. N. Nariswari and N. M. Nugraha, "Profit growth: impact of net profit margin, gross profit margin and total assests turnover," International Journal of Finance \& Banking Studies (2147-4486), vol. 9, no. 4, pp. 87-96, 2020.

[3] M. S. Liu, "What information in financial statements could be used to predict the risk of equity investment?" Journal of Risk and Financial Management, vol. 14, no. 8, 2021.

[4] N. Dogan and H. Adanacioglu, "Performance evaluation of beekeeping farms: a case study from gumushane, Turkey," Pakistan Journal of Zoology, vol. 53, no. 5, pp. 1837-1846, 2021.

[5] I. Fisher, "The economics of accountancy," The American Economic Review, vol. 20, no. 4, pp. 603-618, 1930.

[6] G. J. Staubus, "Comments on "accounting and reporting standards for corporate financial statements-1957 revision"," The Accounting Review, vol. 33, no. 1, pp. 11-24, 1958.

[7] AAA, "Accounting principles underlying corporate financial statements," The Accounting Review, vol. 16, no. 2, pp. 133139, 1941

[8] D. Solomons, "Economic and accounting concepts of income," The Accounting Review, vol. 36, no. 3, pp. 374-383, 1961.

[9] E. S. Hendriksen, Accounting Theory, R. D. Irwin, Homewood, IL, USA, 1965.

[10] E. O. Edwards and P. W. Bell, The Theory and Measurement of Business Income, University of California Press, Berkeley, CA, USA, 1965.

[11] AAA, "Accounting and reporting standards for corporate financial statements 1957 revision," The Accounting Review, vol. 32, no. 4, pp. 536-546, 1957.

[12] D. Drinkwater and J. D. Edwards, "The nature of taxes and the matching principle," The Accounting Review, vol. 40, no. 3, pp. 579-582, 1965.

[13] D. P. Hylton, "On matching revenue with expense," The Accounting Review, vol. 40, no. 4, p. 824, 1965.

[14] I. D. Dichev and W. T. Vicki, "Matching and the changing properties of accounting earnings over the last 40 years," The Accounting Review, vol. 83, no. 6, pp. 1425-1460, 2008.

[15] D. C. Donelson, R. Jennings, and J. McInnis, "Changes over time in the revenue-expense relation: accounting or economics?" The Accounting Review, vol. 86, no. 3, pp. 945-974, 2011.

[16] R. Ball and P. Brown, "An empirical evaluation of accounting income numbers," Journal of Accounting Research, vol. 6, no. 2, pp. 159-178, 1968.

[17] S. P. Kothari and J. L. Zimmerman, "Price and return models," Journal of Accounting and Economics, vol. 20, no. 2, pp. 155-192, 1995.

[18] E. F. Fama and K. R. French, "A five-factor asset pricing model," Journal of Financial Economics, vol. 116, no. 1, pp. 1-22, 2015.

[19] S. J. Eady, "Evaluation of equipment for breeding does housed under Australian meat rabbit farming conditions," Animal Production Science, vol. 49, no. 8, pp. 717-726, 2009.

[20] D. L. Rankins and J. W. Prevatt, "SOUTHERN SECTION INTERDISCIPLINARY BEEF CATTLE SYMPOSIUM: forage and co-product systems for stockers in the south: have fundamental shifts in markets changed the optimal system?" Journal of Animal Science, vol. 91, no. 1, pp. 503-507, 2013.

[21] G. Gajic, S. Stankovski, and G. Ostojic, "Method of evaluating the impact of ERP implementation critical success factors-a case study in oil and gas industries," Enterprise Information Systems, vol. 8, no. 1, pp. 84-106, 2014.

[22] M. E. Bulak and A. Turkyilmaz, "Performance assessment of manufacturing SMEs: a frontier approach," Industrial Management \& Data Systems, vol. 114, no. 5, pp. 797-816, 2014.

[23] A. de Waal and A. Meingast, "Applying the high performance organisation framework in the horticulture and greenhouse 
sector," Measuring Business Excellence, vol. 21, no. 2, pp. 136-151, 2017.

[24] A. Huttinger, L. Brunson, C. L. Moe et al., "Smallwater enterprise in rural Rwanda: business development and year-one performance evaluation of nine water kiosks at health care facilities," International Journal of Environmental Research and Public Health, vol. 14, no. 12, 2017.

[25] L. Jiang, Y. Li, and L. Cai, "Evaluation of enterprise economic performance based on principal component analysis," Journal of Interdisciplinary Mathematics, vol. 21, no. 5, pp. 1309-1314, 2018.

[26] E. K. Tekez, F. Kar, and M. C. Toklu, "A new model for continuous evaluation of suppliers with real execution data," Journal of Engineering Research, vol. 7, no. 2, pp. 298-314, 2019.

[27] S. Y. Kim, H. Shin, and S. Yu, "Do state-owned enterprises cooperate with suppliers? performance analysis in the Korean case," Emerging Markets Finance and Trade, vol. 55, no. 5, pp. 1137-1152, 2019.

[28] L. Ouyang and D. You, "Measurement method of economic difference of export-oriented green innovation economy in coastal cities based on taier index," Journal of coastal Research, no. 83, pp. 817-823, 2019.

[29] I. Khajar, H. Hersugondo, and U. Udin, "Privatization and financial performance: evidence from Indonesia," QualityAccess to Success, vol. 20, no. 173, pp. 107-110, 2019.

[30] X. Wei, H. Khachatryan, and A. Rihn, "Production costs and profitability for selected greenhouse grown annual and perennial crops: partial enterprise budgeting and sensitivity analysis," HortScience, vol. 55, no. 5, p. 637, 2020.

[31] B. J. Henderson and J. M. Marks, "Predicting forecast errors through joint observation of earnings and revenue forecasts," Journal of Banking \& Finance, vol. 37, no. 11, pp. 4265-4277, 2013.

[32] Khatoon S., Ibraheem, Singh A K Effects of Various Factors on Electric Load Forecasting: An Overview: 2014 6TH IEEE POWER INDIA INTERNATIONAL CONFERENCE (PIICON). 6th IEEE Power India International Conference (PIICON): 2014.

[33] M. Mokhtar, A. Shuib, and D. Mohamad, Identifying the Critical Financial Ratios for Stocks Evaluation: A Fuzzy Delphi Approach: INTERNATIONAL CONFERENCE ON QUANTITATIVE SCIENCES AND ITS APPLICATIONS (ICOQSIA 2014)[Z]. Ibrahim H, Zulkepli J, Aziz N, et al. 3rd International Conference on Quantitative Sciences and Its Applications (ICOQSIA): 2014: 1635, 348-354.

[34] T. Van Calster, B. Baesens, and W. Lemahieu, "ProfARIMA: a profit-driven order identification algorithm for ARIMA models in sales forecasting," Applied Soft Computing, vol. 60, pp. 775-785, 2017.

[35] B. An, H. Chen, N. Park, and V. S. Subrahmanian, "Datadriven frequency-based airline profit maximization," ACM Transactions on Intelligent Systems And Technology, vol. 8, no. 4, 2017.

[36] A. Bahar, N. M. Noh, and Z. M. Zainuddin, "Forecasting model for crude oil price with structural break," Malaysian Journal of Fundamental and Applied Sciences, vol. 13, pp. 421-424, 2017.

[37] A. Patel, H. S. V. S. Nunna, and S. Doolla, "Multi-agent-based forecast update methods for profit enhancement of intermittent distributed generators in a smart microgrid," Electric Power Components and Systems, vol. 46, no. 16-17, pp. 1782-1794, 2018.
[38] N. I. Lomakin, E. E. Kharlamova, and A. A. Polyanskaya, Sustainable development of regional enterprises based on the neural network profit forecasting model: PROCEEDINGS OF THE INTERNATIONAL SCIENTIFIC CONFERENCE COMPETITIVE, SUSTAINABLE AND SECURE DEVELOPMENT OF THE REGIONAL ECONOMY: RESPONSE TO GLOBAL CHALLENGES (CSSDRE 2018)[. Russkova E G. International Scientific Conference on Competitive, Sustainable and Secure Development of the Regional Economy Response to Global Challenges (CSSDRE): 2018: 39, 113-116.

[39] C. S. A. Cheng, K. C. K. Chu, and J. Ohlson, "Analyst forecasts: sales and profit margins," Review of Accounting Studies, vol. 25, no. 1, pp. 54-83, 2020.

[40] M. T. Fulop, A. Szora Tamas, O. R. Ivan, and A. N. Solovastru, "Regressive model regarding the necessary profit margin forecast for a new project in the constructions field," Economic Computation and Economic Cybernetics Studies and Research, vol. 54, no. 2, pp. 181-198, 2020.

[41] Y. Fang, X. Wang, and J. Yan, "Green product pricing and order strategies in a supply chain under demand forecasting," Sustainability, vol. 12, no. 2, 2020.

[42] N. M. Bedford, "The nature of business costs, general concepts," The Accounting Review, vol. 32, no. 1, pp. 8-14, 1957.

[43] A. C. Littleton, "What is profit?" The Accounting Review, vol. 3, no. 3, pp. 278-288, 1928.

[44] T. J. Phillips Jr., M. S. Luehlfing, and C. M. Daily, “The right way to recognize revenue," Journal of Accountancy, vol. 191, no. 6, p. 39, 2001.

[45] E. A. Heilman, "Realized income," The Accounting Review, vol. 4, no. 2, pp. 80-87, 1929.

[46] C. A. S. R. Committee, “The realization concept," Accounting Review, vol. 40, no. 2, pp. 312-322, 1965.

[47] R. J. Chambers, "Edwards and bell on business income," Accounting Review, vol. 40, no. 4, pp. 731-741, 1965.

[48] P. M. Fairfield, K. A. Kitching, and V. W. Tang, "Are special items informative about future profit margins?" Review of Accounting Studies, vol. 14, no. 2-3, pp. 204-236, 2009. 